\title{
A further investigation of the development of mouse-killing in rats
}

\author{
Norman W. Heimstra \\ UNIVERSITY OF SOUTH DAKOTA
}

\begin{abstract}
Several previous investigations have suggested that competitive experience is an important factor in the development of the mouse-killing response in rats. However, the question of whether the competition involved or food deprivation associated with the competition is the critical factor has been raised. In the present study three groups of rats were used. In one group $(\mathrm{N}=40)$ rats were food deprived and were placed daily, in pairs, in a situation where they could compete for food. A second group $(\mathrm{N}=20)$ was food deprived but not exposed to the competitive situation, while a third group $(\mathrm{N}=20)$ was not food deprived. Animals were tested daily for 15 consecutive days for the development of the killing response. Rats in the group receiving both food deprivation and competitive experience killed significantly more mice than rats in the other groups.

\section{Introduetion}

The killing response of the rat toward the mouse has been subjected to a variety of investigations. Karli $(1956,1958,1959,1961)$ attempted to determine the physiological, environmental and genetic factors involved in the killing response as well as surgical and pharmacological methods of modifying the response. Heimstra \& Newton (1961) investigated the effects of past experience, in the form of competition for food, on the killing response and concluded that competition was an important variable in bringing about the response. In a recent study by Whalen \& Fehr (1964), however, which replicated part of the Heimstra and Newton study, it was found that food deprivation appeared to be of primary importance in facilitating the killing response and that competition, as such, was of relatively little importance. The purpose of the present experiment was to re-examine, by a modified procedure, the effect of competition and food deprivation on the development of the killing response to mice.
\end{abstract}

\section{Method}

A number of adult albino rats of Wistar origin were tested to determine whether they would spontaneously kill mice. The test consisted of placing a mouse in the cage of each rat and leaving it there for a $30-\mathrm{min}$. period. Eighty rats were selected from the animals that did not kill and were used as Ss. These animals were housed individually during the course of the study.

Ss were divided into three groups: CompetitiveDeprived (C-D, N=40); Deprived (D, N=20); and Control $(C, N=20)$. In the $C-D$ group the rats were deprived of food for $22 \mathrm{hr}$. and then placed in pairs in a $24 \times 12 \times 12$ in wooden box with a hardware cloth top and bottom. The same animals were paired on each successive day. A metal food container, 2 in high and 1 in in diameter, was secured to the center of the floor of the test box. Only one rat of a pair could eat from this container which held moistened, ground laboratory pellets. A pair of rats was left in this situation for $5 \mathrm{~min}$. and then returned to their individual home cages. Animals were then allowed free access to food pellets for slightly less than $2 \mathrm{hr}$. At that time the excess pellets were removed from the cage and an adult white mouse was placed in the cage. The mouse was left in the cage for $30 \mathrm{~min}$. at which time it was removed if it had not been killed. Once a rat killed a mouse it was no longer tested for the killing response. However, it was still food deprived and paired each day in the competitive situation with the rat that it had been paired with initially. Once both rats of a pair had killed, they were eliminated from the study.

Rats in the D group were treated in a manner similar to the animals in the C-D group. However, they were placed individually in the competition box, allowed to remain for $5 \mathrm{~min} .$, and were then returned to their home cages. After the feeding session in the home cage a rat was tested for the mouse-killing response. After a rat killed it was no longer used in the investigation. In the case of the rats from the $C$ group, food was available at all times. They were placed in the competition box individually for $5 \mathrm{~min}$., returned to their cages, and $2 \mathrm{hr}$. later tested for the killing response. These procedures were followed daily for 15 consecutive days.

In the present investigation five competition boxes were used simultaneously. This allowed for placing all Ss in a competition box and following the procedures decribed above during a $3 \mathrm{hr}$. afternoon session.

The principal difference between the methods employed in this study and the investigation by Heimstra and Newton and by Whalen and Fehr was that the rats were tested each day for the development of the killing response. In the previous studies testing for this response was done only once at the end of the 15 days.

\section{Results and Diseussion}

The cumulative frequency of killing by rats in each of the groups was obtained. At the end of five days of testing, 2 rats in the C-D group had killed, 1 rat in the $\mathrm{D}$ group and 2 rats in the $\mathrm{C}$ group. At the end of 10 days, 13 rats in the C-D group had killed, 3 in the D group and 3 in the $C$ group. By the end of the 15th test session, 24 rats in the C-D group had killed, 6 in the D group 
and 4 in the $\mathrm{C}$ group. Chi-square analysis of these latter data yielded a $\mathrm{X}^{2}$ of 10.42 which is significant at the .01 level.

Data from the present investigation support the conclusion that prior competitive experience is of importance in the development of the killing response in rats. Findings in this study are similar to those reported in the Heimstra and Newton investigation where it was found that rats tested for the mousekilling response after 15 days, during which they were exposed to daily food competition, killed significantly more mice than rats that did not receive this type experience. Results of the present investigation further indicate that food deprivation does not appear to be a critical variable in the development of the killing response. This conclusion is also substantiated in a study by Sorenson (1962) in which rats that had been food deprived and exposed to food competition killed more mice than did rats that had only been food deprived.

It is difficult to account for the discrepancy between findings of the present investigation, as well as earlier studies (Heimstra \& Newton, 1961, Sorensen, 1962), and the study by Whalen and Fehr. Although the deprivation variable was not taken into account in the Heimstra and Newton study, the present investigation as well as the study by Sorensen suggests that this is not a major factor in bringing about the killing response. Rather, these studies suggest that some aspect of the experience encountered in the competitive situation is critical. Unfortunately, it is not possible to determine from the studies completed just what element of the situation facilitates the response. However, on the basis of these investigations, one can tentatively eliminate some factors of the competitive situation which do not appear to be of importance in developing the killing response. One of the most obvious forms of behavior demonstrated when the pair of rats is placed in the food competition box is fighting. However, in the Heimstra and Newton

\section{Comment}

In a recent paper Ehrenfreund \& Allen (1964) have taken issue with Gleitman \& Steinman (1963) who had reported that forgetting of an instrumental response may occur in the absence of any explicit interference. Gleitman and Steinman had shown a decrement in the runway performance of rats following a two-month retention interval but Ehrenfreund and Allen argued that this decrement could be ascribed to a failure to maintain the "total motivational level" over this two-month period. To support this contention they ran 14 rats on a runway for 17 days at five trials per day, testing them after 27 days during which the Ss' body weight was maintained continuously and automatically by a procedure developed by Ehrenfreund (1960). Terminal speeds showed a retention loss while running speeds did not. The authors concluded that performance decrements of the kind shown by Gleitman and Steinman study no relationship was found between the amount of time a pair of rats spent in fighting and whether they killed mice. It was also suggested in that investigation that stress involved in the competition for food might account for the development of the response. If stress was a contributing factor one might expect that the submissive rats would develop the tendency to kill rather than the dominant animals. This assumption is based on studies reviewed by Thiessen \& Rodgers (1961) which report that submissive rats or mice are stressed more than the dominant animals. However, in the Heimstra and Newton study 16 of the 22 rats that killed were dominant.

One possible explanation for the different results obtained by Whalen and Fehr may rest in the strain of rats utilized as Ss. They used rats of the SpragueDawley and Long-Evans strains. Rats of Wistar origin were used in the present investigation as well as the earlier investigation and the study by Sorensen. The possibility exists that rats of different strains may not react similarly to the experience encountered in the competitive situation.

\section{References}

HEIMSTRA, N. W., \& NEWTON, G. Effects of prior food competition on the rat's killing response to the white mouse. Behaviour, 1961, 17, 95-102.

KARLI, P. The Norway rat's killing response to the white mouse. Behavior, 1956, 10, 81-103.

KARLI, P. Action de l'amphetamine et de la chlorpromazine sur l'agressitité interspécifique Rat-Souris. Comptes rendus des séances de la Société de Biologie, 1958, 152, 1796.

KARLI, P. Recherches Pharmacologiques sur le comportement d'agression Rat-Souris. J. Physiol., Paris, 1959, 51, 497-498.

KARLI, P. Nouvelles données expérimentales sur le comportement d'agression interspecifique Rat-Souris. J. Physiol., Paris, 1961, 53, 383-384.

SORENSEN, D. M. Effects of competition for food on the development of the rat's response of killing white mice. Unpublished M. A. thesis, University of South Dakota, 1962.

THIESSEN, D. D., \& RODGERS, D. A. Population density and endocrine function. Psychol. Bull., 1961, 58, 441-451.

WHALEN, R. E., \& FEHR, H. The development of the mouse-killing response in rats. Psychon. Sci., 1964, 1, 77-78.

should be attributed to motivational changes rather than to forgetting. This conclusion is open to question on several counts:

(1) There are a considerable number of procedural differences between the two experiments in addition to the drive maintenance techniques that could account for the failure to find forgetting in the Ehrenfreund and Allen study: Their Ss were given more practice (85 vs. 20 trials) and were tested after a shorter retention interval (27 vs. 64 days) than those of Gleitman and Steinman; the expected effect of such procedural changes is clearly to reduce retention loss. In addition, their study lacks a control group tested some short time interval after training to assess the effect of post-criterial bias and of further training due to reinforced test trials.

(2) Ehrenfreund and Allen emphasize the one response measure (running speed in a middle section of the

(Continued on page 210) 